\title{
Pengembangan Digital Branding Kampung Hidropononik Medokan Ayu Surabaya
}

\author{
Jokhanan Kristiyono, Muhammad Reza Patriagama, Adi Atma, Indra Septyan, Rizal Hanafi, \\ Habib Syahrul Asrori
}

\author{
Program Studi Ilmu Komunikasi \\ Stikosa-AWS \\ Nginden Inten Timur 1/18, Surabaya \\ Email: jokhanan.k@stikosa-aws.ac.id
}

\begin{abstract}
Nowdays, the flagship product of Medokan Ayu Hydroponic Village is only known locally in the area around Rungkut District, Surabaya. The persistence of the people of Medokan Ayu Surabaya Hydroponic Village to care for and develop these plants, it is very unfortunate if just known locally. It is necessary to introduce superior products to the wider community. With the support of the internet and the information community network, the superior products of the Hydroponic Village can be known much more widely. The method used in solving problems in the development of superior product branding in Medokan Ayu Surabaya Hydroponic Village is in the form of implementing research-based community service. There are 2 (two) stages in the implementation method, namely the first is research and the second is the implementation of research-based activities. The research carried out is product research with observations of producers and consumers as the target market for vegetable products from the Hidroponics Village of Medokan Ayu Surabaya. Next, data management from research results in the first stage which is the basis for the development of the product branding of Medokan Ayu Hydroponic Village. Through these 9 (nine) programs aimed at developing branding through social media, information about superior hydroponic products from Medokan Ayu can be known to all residents of the City of Surabaya locally, Indonesian people nationally to internationally globally. As a result, 9 work programs have been implemented, there are 2 (two) programs that have not been implemented optimally, namely making packaging and socializing digital media for the community of Medokan Ayu Hidroponik village. This is because the Covid-19 pandemic in the city of Surabaya has to carry out a health protocol with restrictions on activities that gather the masses, so socialization and assistance activities for the use of digital media as digital media branding have not been carried out optimally. But this was not an obstacle, finally the implementation was done online (online) through Google Meet and video tutorials.
\end{abstract}

Keywords: Hydroponic, Medokan Ayu Village, Community Service, Research Based, Pandemic Covid-19, Digital Branding

\begin{abstract}
Abstrak
Produk unggulan Kampung Hidroponik Medokan Ayu saat ini hanya dikenal secara lokal daerah sekitar Kecamatan Rungkut Surabaya. Kegigihan masyarakat Kampung Hidroponik Medokan Ayu Surabaya untuk merawat dan mengembangkan tanaman tersebut, sangat disayangkan apabila hanya dikenal oleh warga sekitar saja. Perlu adanya pengenalan produk unggulan kepada masyarakat yang lebih luas. Dengan adanya dukungan internet dan jejaring masyarakat informasi, maka produk unggulan dari Kampung Hidroponik tersebut dapat dikenal jauh lebih luas. Metode yang digunakan dalam pemecahan permasalahan pada pengembangan branding produk unggulan Kampung Hidroponik Medokan Ayu Surabaya ini merupakan dalam bentuk pelaksanaan pengabdian masyarakat berbasis riset. Ada 2 (dua) tahapan dalam metode pelaksanaan yaitu pertama adalah riset dan kedua adalah pelaksanaan kegiatan berbasis riset. Riset yang dilakukan adalah riset produk dengan observasi produsen dan konsumen sebagai target pasar produk sayuran dari Kampung Hidroponik Medokan Ayu Surabaya. Berikutnya adalah pengelolaan data hasil riset pada tahap pertama menjadi dasar pelaksanaan pengembangan branding produk Kampung Hidroponik Medokan Ayu. Melalui 9 (Sembilan) program pengabdian masyrakat ini bertujuan untuk pengembangan branding melalui sosial media, maka informasi tentang produk unggulan hidroponik dari Medokan Ayu ini dapat
\end{abstract}


dikenal pada seluruh penduduk Kota Surabaya secara lokal, masyarakat Indonesia secara nasional hingga mancanegara secara global. Hasilnya, 9 program kerja yang sudah terlaksana, terdapat 2 (dua) program yang tidak dapat terlaksana dengan optimal, yaitu pembuatan kemasan dan sosialisasi media digital untuk masyarakat kampung Hidroponik Medokan Ayu. Ini dikarenakan terjadi pandemic Covid-19 kota Surabaya harus melakukan protokol kesehatan dengan batasan kegiatan yang mengumpulkan massa, maka kegiatan sosialisasi dan pendampingan penggunaan media digital sebagai media digital branding belum terlaksana dengan optimal. Tetapi hal itu tidak menjadi kendala, akhirnya pelaksanaannya dilakukan secara daring (dalam jaringan) melalui medium Google Meet dan video tutorial.

Kata Kunci: Sayur Hidroponik, Kampung Medokan Ayu, Pandemik Covid-19, Digital Branding, Pengabdian Masyarakat berbasis Riset

\section{PENDAHULUAN}

Kota Surabaya merupakan salah satu kota metropolitan di Indonesia yang memiliki jumlah penduduk sebanyak 3.158 .943 orang, dengan luas wilayah 326,81 km2 yang terbagi dari 4 wilayah yaitu Surabaya Utara, Surabaya Selatan, Surabaya Barat, dan Surabaya. Kota Surabaya memiliki 31 Kecamatan dan 154 Kelurahan. Surabaya memiliki lokasi kependudukan yang beragam, mulai dari lokasi pemukiman hingga lokasi pusat bisnis (sumber: data BPS Kota Surabaya 2020, https://surabayakota.bps.go.id/, terakhir akses: 20 Februari 2021). Meskipun memiliki banyak lokasi pusat bisnis dan pusat perbelanjaan modern di masingmasing wilayah, Kota Surabaya juga memiliki permukiman penduduk yang tidak meninggalkan budaya Indonesia sebagai negara agraris. Pada data Badan Statistik Kota Surabaya tahun 2020, terdapat 3 (tiga) besar produksi tanaman sayur dan 3 (tiga) besar produksi tanaman Biofarmaka.

Pada era modern saat ini, budaya agraris cukup sulit dilakukan pada kota besar seperti Kota Surabaya. Ini dikarenakan semakin sedikitnya lokasi perkebunan atau pertanian yang bisa dilakukan di kota besar seperti Kota Surabaya. Kebutuhan pangan khususnya sayuran pada masyarakat perkotaan dan lokasi pertanian yang cukup jauh hingga membutuhkan waktu tersendiri agar dapat memenuhinya, maka dibutuhkan pola tanam sayuran yang dapat dilakukan di perkotaan. Menurut Balai Penelitian Tanaman Sayura (2005), budidaya tanaman sayuran dengan sistem hidroponik merupakan metode penanaman tanaman tanpa menggunakan media tumbuh dari tanah. Secara harfiah, hidroponik berarti penanaman dalam air yang mengandung campuran hara (Rosliani \& Sumarni, 2005). Metode tanam hidroponik terkenal dengan kemudahannya dalam menanam sayuran. Metode tanam sayuran ini menjadi sistem penamaman sayuran yang menjadi pilihan bagi para penduduk kota besar seperti Surabaya. Salah satunya adalah penduduk Kelurahan Medokan Ayu, Kecamatan Rungkut Kota Surabaya.

Kampung Hidroponik yang berada di Medokan Ayu Surabaya, tepatnya di RW 12 ini mendapat sorotan cukup bagus untuk semakin dikenal luas oleh Masyarakat Surabaya. Mengingat bahwa lahan untuk bercocok tanam di Surabaya semakin susah untuk dicari. Kampung Hidroponik di Medokan Ayu melakukan berbagai inovasi budaya agraria dengan menerapkan perawatan dan pengembangan pada tanaman hidroponik. Beragam jenis tanaman sayuran seperti Sawi Pak Choy, Kangkung, Selada, Bayam, dan masih banyak lagi yang ditanam pada Kampung Hidropronik Medokan Ayu ini. Budidaya hidroponik ini berawal pada tahun 2020 
yang digagas oleh Ibu Reni. Beliau merupakan koordinator pengembangan tanaman hidroponik dengan bantuan Coorporate Social Responbility (CSR) dari Bank Danamon. Antusisas warga RW 12 yang dihelat oleh RT 4 dan RT 5 menjadi kegiatan baru diawal tahun 2020. Melalui beragam kegiatan sosialisasi dan pendampingan selama 6 bulan lebih pada tahun 2019, saat ini terdapat 5 kebun di lokasi pemukiman warga RW 12 kelurahan Medokan Ayu ini.

Permasalahan yang saat ini muncul adalah produk unggulan Kampung Hidroponik Medokan Ayu ini hanya dikenal secara lokal daerah sekitar Kecamatan Rungkut Surabaya. Kegigihan masyarakat Kampung Hidroponik Medokan Ayu Surabaya untuk merawat dan mengembangkan tanaman tersebut, sangat disayangkan apabila hanya dikenal oleh warga sekitar saja. Untuk mengatasi permasalahan tersebut perlu adanya pengenalan produk unggulan kepada masyarakat yang lebih luas (Cocoran, 2010). Dengan adanya dukungan internet dan jejaring masyarakat informasi, maka produk unggulan dari Kampung Hidroponik tersebut dapat dikenal lebih luas (Kristiyono, 2017). Pengembangan branding melalui sosial media, maka informasi tentang produk unggulan hidroponik dari Medokan Ayu ini dapat dikenal pada seluruh penduduk Kota Surabaya secara lokal, masyarakat Indonesia secara nasional hingga mancanegara secara global (Rowles, 2014).

Para produsen barang atau produk seperti sayuran hidroponik telah menggunakan merek (brand) untuk membedakan produk mereka dengan produk lain. Lebih khusus lagi, dengan mengidentifikasi produk mereka, mereka telah memberikan cara kepada pembeli untuk mengenali dan menentukan mereka jika mereka ingin membeli kembali atau merekomendasikan produk tersebut kepada orang lain (Murphy, 1992). Murphy (1992) pada bukunya yang berjudul "Branding: A Key Marketing Tool" menjelaskan bahwa penggunaan merek (branding) oleh produsen telah berkembang pesat selama beberapa puluh tahun ini, terutama pada era tahun 1990an. Namun fungsi merek sebagai pembeda barang satu produsen dengan yang lainnya tetap tidak berubah. Cara merek telah berkembang selama bertahuntahun pada dasarnya tiga kali lipat. Pertama, sistem hukum telah mengakui nilai merek baik bagi produsen maupun konsumen. Sebagian besar negara di dunia sekarang mengakui bahwa kekayaan intelektual - merek dagang, paten, desain, hak cipta - adalah milik dalam arti yang sangat nyata dan oleh karena itu memberikan hak kepada pemilik property atau produk tersebut.

Kedua, konsep barang bermerek (brand) telah diperluas dengan adanya layanan. Dengan demikian, penyedia layanan keuangan, ritel, atau lainnya sekarang secara umum dapat memperlakukan mereka sebagai produk bermerek, asalkan tetap ada pembeda dari pesaing atau kompetitor. Begitu juga dengan produk sayuran seperti hidroponik dari Medokan Ayu, harus dapat mengembangkan merek nya dengan adanya layanan yang baik dan unggul, juga terdapat perbedaan dengan kompetitornya. Ketiga, dan mungkin yang paling penting, cara membedakan produk atau layanan bermerek satu sama lain semakin mencakup faktor-faktor non-nyata, dan faktor-faktor nyata seperti kemasan, ukuran, bentuk, logo, dan harga. Kualitas merek yang diandalkan konsumen dalam menentukan pilihan mereka di antara merek produk yang sama terkadang berubah-ubah. Itu menjadi tantangan tersendiri dari produsen agar memahami konsumennya.

Namun saat ini pada era informasi dan media digital, konsumen tidak memilih-milih dalam hubungan merek mereka (Edelman, 2010). Konsumen terhubung dengan berbagai merek melalui saluran media baru di luar kendali produsen dan penjual. Setelah pembelian, konsumen ini dapat tetap terlibat secara 
agresif terhadap produk yang sudah dibelinya atau dikonsumsinya, secara publik konsumen dapat langsung mempromosikan atau menyerang produk yang telah mereka beli. Konusmen dapat berkolaborasi dalam pengembangan merek, sekaligus menantangnya serta membentuk makna apa yang mereka rasakan dan pahami. Konsumen pada masyarakat informasi merupakan konsumen yang aktif dan cerdas dalam menggunakan media komunikasi. Konsumen masih menginginkan janji merek yang ditawarkan oleh produsen dan penjual (Susilo, 2020).

Ini merupakan tantangan yang harus dihadapi oleh produsen seperti Kampung Hidroponik Medokan Ayu Surabaya. Konsumen produk sayuran hidroponik merupakan konsumen dari masyarakat kota yang memiliki selera konsumsi makanan yang cukup berbeda dengan yang lain. Konsumen ini juga merupakan masyarakat informasi yang berjejaring, mencari informasi produk-produk yang mereka inginkan menggunakan media informasi jejaring seperti media sosial (Castells, 2011). Mereka paling terbuka untuk dipengaruhi, dan bagaimana produsen dapat berinteraksi dengan konsumen pada titik-titik tersebut yaitu melalui media informasi digital (Kristiyono \& Jayanti, 2017).

Fenomena sosial dan permasalahan yang ada pada Kampung Hidroponik Medokan Ayu Surabaya ini adalah bagaimana produk sayuran hidroponik sebagai produk unggulan dapat dikenal lebih luas pada masyarakat kota Surabaya hingga mancanegara secara global. Ini merupakan tantangan tersendiri dalam mengembangkan branding pada era media informasi digital. Kampus Stikosa-AWS memiliki civitas akademik yang paham dan mengerti tentang branding dan pengelolaan media komunikasi digital. Civitas akademik kampus yang terdiri dari dosen dan mahasiswa dalam hal ini turun ke masyarakat langsung untuk membantu pengembangan brand produk Kampung Hidroponik Medokan Ayu Surabaya sebagai bentuk kegiatan pengabdian masyarakat.

\section{METODE PELAKSANAAN}

Metode yang digunakan dalam pemecahan permasalahan pada pengembangan branding produk unggulan Kampung Hidroponik Medokan Ayu Surabaya ini merupakan dalam bentuk pelaksanaan pengabdian masyarakat berbasis riset. Terdapat 2 (dua) tahapan dalam metode pelaksanaan yaitu pertama adalah riset. Pada tahapan pertama ini, dilakukan riset produk yang bertujuan untuk mengenal produk unggulan dan produsen unggulan tersebut. Setelah riset produk, dilakukan observasi khalayak sebagai target pasar produk sayuran dari Kampung Hidroponik Medokan Ayu Surabaya atau dapat disebut target konsumen. Pada observasi konsumen ini, dapat dipetakan secara sederhana apa saja produk-produk sayuran yang diminati oleh konsumen, sosial ekonomi konsumen, hingga pola media komunikasi yang digunakan konsumen dalam mencari informasi.

Tahapan kedua adalah pengelolaan data hasil riset pada tahap pertama menjadi dasar pelaksanaan pengembangan branding produk Kampung Hidroponik Medokan Ayu. Pada tahapan ini, data-data riset menjadi acuan dalam pengembangan produk khususnya pada penyebaran informasi pada konsumen melalui media komunikasi digital. Digital branding Kampung Hidroponik Medokan Ayu Surabaya ini adalah cara bagaiaman produk sayuran hidroponik sebagai produk unggulan dapat dikenal oleh masyarakat kota Surabaya lebih luas hingga memberikan informasi produk sayuran hidroponik secara global melalui media informasi berbasis Internet. Ini adalah pelaksanaan pengembangkan branding pada era media informasi digital untuk Kampung Hidroponik Medokan Ayu Surabaya yang dilakukan civitas 
akademik Stikosa-AWS. Masyarakat akademik yang paham dan mengerti tentang branding hingga cara pengelolaan media komunikasi digital.

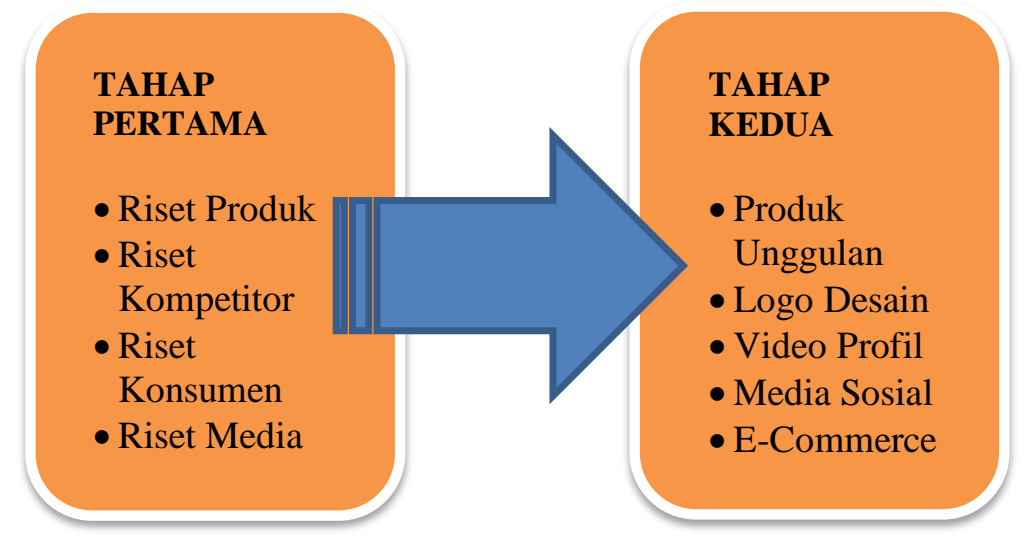

Gambar 1. Tahapan Pelaksanaan Pengabdian Masyarakat

Metode pelaksanaan pengabdian masyarakat ini berbasis riset studi kuantitatif dengan terjun langsung ke lapangan untuk melihat keadaan tempat yang akan diteliti. Selain itu dilakukan observasi dengan wawancara kebutuhan masyarakat sekitar agar mengetahui kebutuhan-kebutuhan untuk melaksanakan program pengabdian masyarakar. Melalui riset yang sudah dilakukan, munculah beberapa program yang sudah dikompilasi melalui permasalahan yang dimiliki oleh Kampung Hidroponik Medokan Ayu Surabaya.

1. Desain logo paten Kampung Hidroponik Surabaya

2. Kemasan ramah lingkungan produk Kampung Hidroponik Surabaya

3. Video Profile Kampung Hidroponik Surabaya

4. Foto dan Video Profile produk Tanaman Hidroponik

5. Sosial Media Kampung Hidroponik Surabaya

6. Pembuatan E-Commerce seperti Bukalapak, Tokopedia dan Shopee

7. Sosialiasi tentang platform digital

8. Tutorial pembuatan tanaman hidroponik

9. Pembuatan banner untuk pengenalan Kampung Hidroponik Surabaya

Melalui 9 (sembilan) permasalahan yang diketahui lalu diimplementasikan melalui program kerja ini, maka dapat dilaksanakan program "Pendampingan Digital Branding Kampung Hidroponik Medokan Ayu Surabaya".

\section{HASIL DAN PEMBAHASAN}

Pengembangan masyarakat setempat terhadap tanaman Hidroponik sangat pesat setelah beberapa bulan, semenjak dimulai Februari 2020 lalu telah berdiri 4 (empat) kebun baru. dengan penamaan kebun sebagai brand masing-masing yaitu, MU, Guyub Rukun, Hybrid04, dan Hijau Kampungku. Rata-rata penduduk Medokan Ayu Surabaya adalah Pria dengan pekerjaan utama adalah swasta dan Wanita ratarata merupakan ibu rumah tangga, Dengan segala kesibukannya, namun masyarakat disini masih turut andil dalam perawatan dan pengembangan tanaman Hidroponik. Setiap harinya selalu ada yang melakukan pengecekan secara berkala, sesuai dengan jadwal yang ada. Pelaksanaan pengabdian masyarakat ini sangat diterima oleh warga Medokan Ayu khsusunya pada warga RW 12 kelurahan Medokan Ayu Surabaya. 
Selain pengembangan melalui media tanam tersebut menjadi produk unggulan, pengembangan informasi produk melalui sosial media juga menjadi media interaksi dan konektivitas yang tepat bagi masyarakat tersebut dengan konsumennya.

Namun, melihat potensi yang sangat bagus untuk dikenalkan masyarakat secara luas, Kampung Hidroponik Medokan Ayu ini masih memiliki pengetahuan yang sedikit tentang platform digital. Warga setempat hanya mempelajari carai merawat tanaman hidroponik hingga ke tahap panen, lalu dijual dan diolah menjadi produk. Hal tersebut yang mendasari kelompok pengabdian masyarakat StikosaAWS ini untuk membantu mengembangkan melalui platform digital seperti sosial media dan e-commerce.

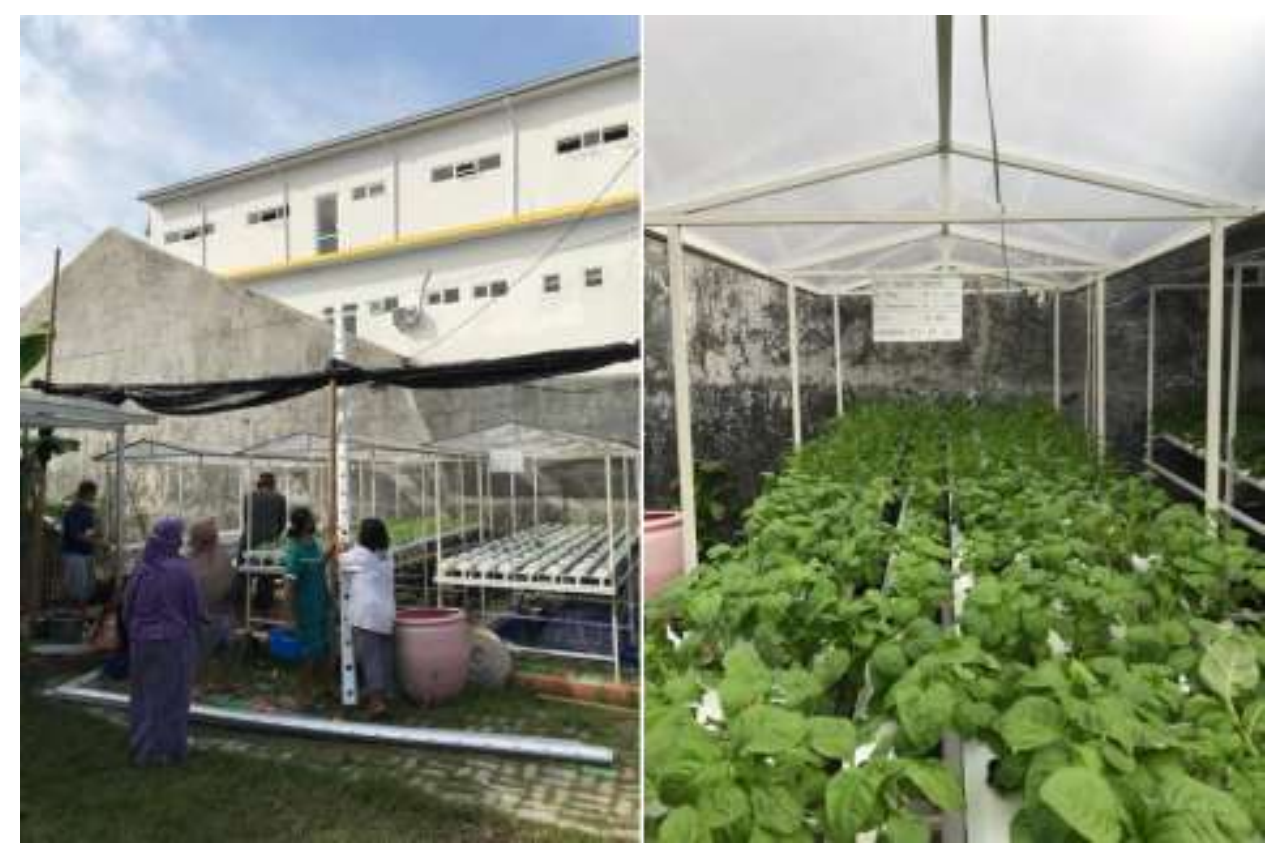

Gambar 2. Salah satu kebun yang ditanami Sawi Pak Choy

di Kampung Medokan Ayu Surabaya

Hidroponik

Berikut ini adalah pelaksanaan pengabdian masyarakat di Kampung

\section{Desain logo paten Kampung Hidroponik Medokan Ayu Surabaya}

Pada kegiatan tahapan pertama, yaitu salah satunya adalah riset produk. Dari observasi dan riset yang telah dilakukan, maka tahapan ini mendapatkan data produsen dan produk unggulan yang dimiliki Kampung Hidroponik Medokan Ayu Surabaya. Ada beberapa hal yang harus ditingkatkan dan dikembangkan agar produk lebih dikenal yaitu Logo Brand. Logo merupakan salah satu elemen branding dari suatu produk. Logo menjadi fungsi identitas sebuah korporat atau produk yang ingin dikenal dan menjadi pembeda dari produk lainnya (Jokhanan, 2020).

Pada kegiatan tahapan kedua ini merupakan implemtasi hasil riset yang sudah dilakukan pada tahap pertama yaitu riset. Desain logo baru yang dibuat merupakan hasil penggambaran tanaman hidroponik sebagai objek utama dari kampung Medokan Ayu ini. Konsep dasar logo melalui penggambaran tangan (sketching) lalu diperbaiki melalui aplikasi grafis Corel Draw. Beberapa konsep logo dibuat lalu ditunjukkan pada produsen (Kampung Hidroponik Medokan Ayu Surabaya). Salah 
satu logo ini disetujui dan disepakati oleh koordinator Kampung Hidroponik, logo yang menjadi identitas produk (brand identity).
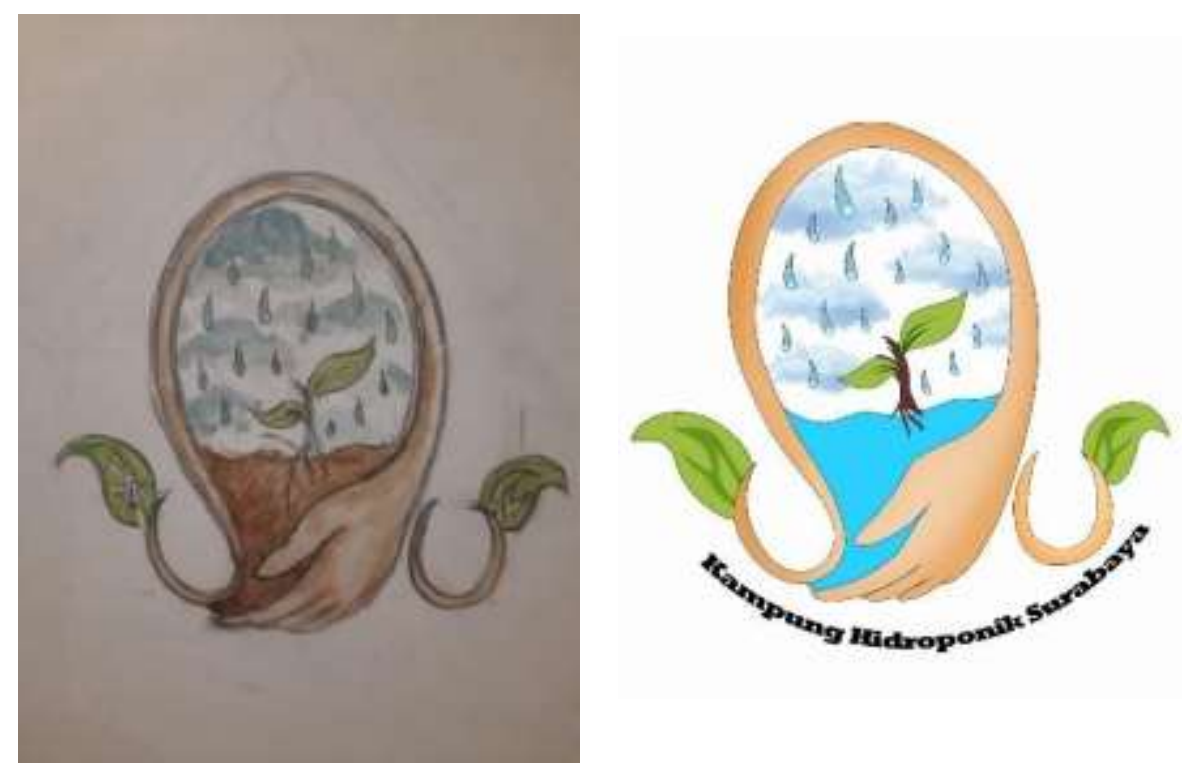

Gambar 3. Desain Logo sebagai Brand Identity Kampung Hidroponik

\section{Desain kemasan ramah lingkungan produk Kampung Hidroponik Surabaya}

Masih dalam pengembangan identitas brand dari produk Kampung Hidroponik Medokan Ayu, kegiatan kedua adalah membuat desain kemasan (packaging).Kemasan untuk produk olahan sayuran hidroponik yang digunakan sebelumnya oleh warga disini yaitu dengan plastik. Pada kegiatan pengabdian masyarakat ini merubah kemasan menjadi lebih ramah lingkungan seperti kertas yang food grade atau aman sebagai tempat kemasan makanan. Produk yang dihasilkan rata-rata keripik dan memiliki kandungan minyak yang cukup banyak, maka dari itu bila menggunakan kertas akan menimbulkan resapan yang bisa memperburuk kemasan tersebut. Selain itu, produk-produk hasil olahan ini akan diproduksi bila ada pameran atau pemesanan.

Kemasan produk pangan metupakan paket kemasan yang memiliki bahan kemasan khusus untuk makanan. Sebuah kemasan yang dapat memberikan perlindungan pada makanan, yang dapat memberikan ketahanan makanan terhadap gangguan, secara fisik, kimia, atau biologis khusus. Kemasan produk pangan ini memuat label fakta nutrisi dan informasi lain tentang makanan yang ditawarkan untuk dijual. 


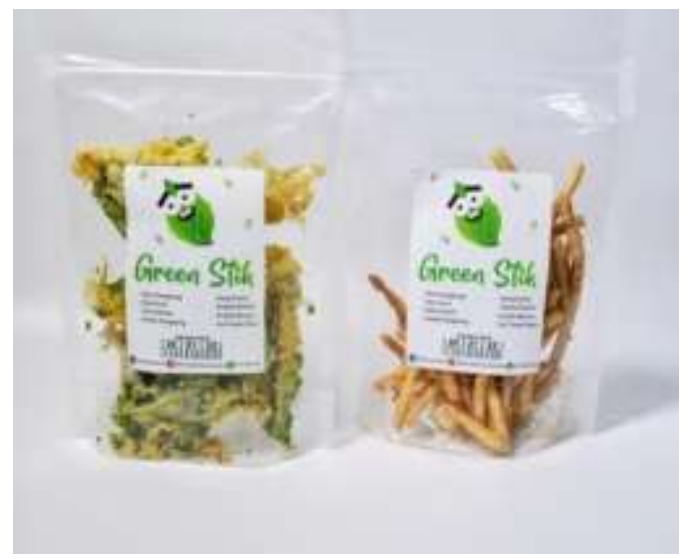

Gambar 4. Foto kemasan produk

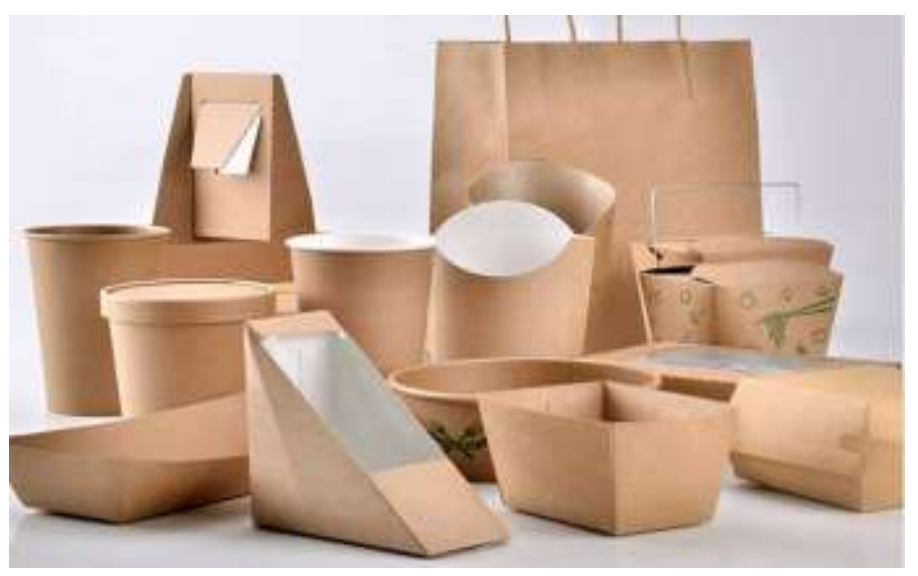

Gambar 5. Konsep rencana kemasan produk

(sumber: https://www.foodpersonality.nl/cba-golfkartonindustrie-sterk-gestegenvraag-aan/)

\section{Video Profile Kampung Hidroponik Surabaya}

Kegiatan berikutnya adalah pembuatan profil produsen dalam bentuk video, yaitu video profil Kampung Hidroponik Medokan Ayu Surabaya. Pengambilan gambar melalui kamera sudah dilaksanakan sejak kegiatan awal pada tanggal 21 Juni 2020. Video profile ini sendiri merupakan pengenalan pada masyarakat luas tentang kampung hidroponik yang berada di Medokan Ayu Surabaya. Untuk pengunggahan video tersebut melalui Youtube dan Instagram.

Video pengenalan ini dilaksanakan sesuai dengan acuan dari storyboard yang dirancang sebelumnya. Keberhasilan pada program kerja ini sesuai karena mengikuti apa yang diinginkan ketua RW 12 untuk mengenalkan kampung hidroponik lebih detail pada masyarakat luas. Video ini nantinya juga akan berfungsi untuk mengenalkan ketika ada pameran sebagai video commercial (Djauhari \& Afniar, 2018). Video ini juga sudah diunggah melalui platform digital Youtube. 


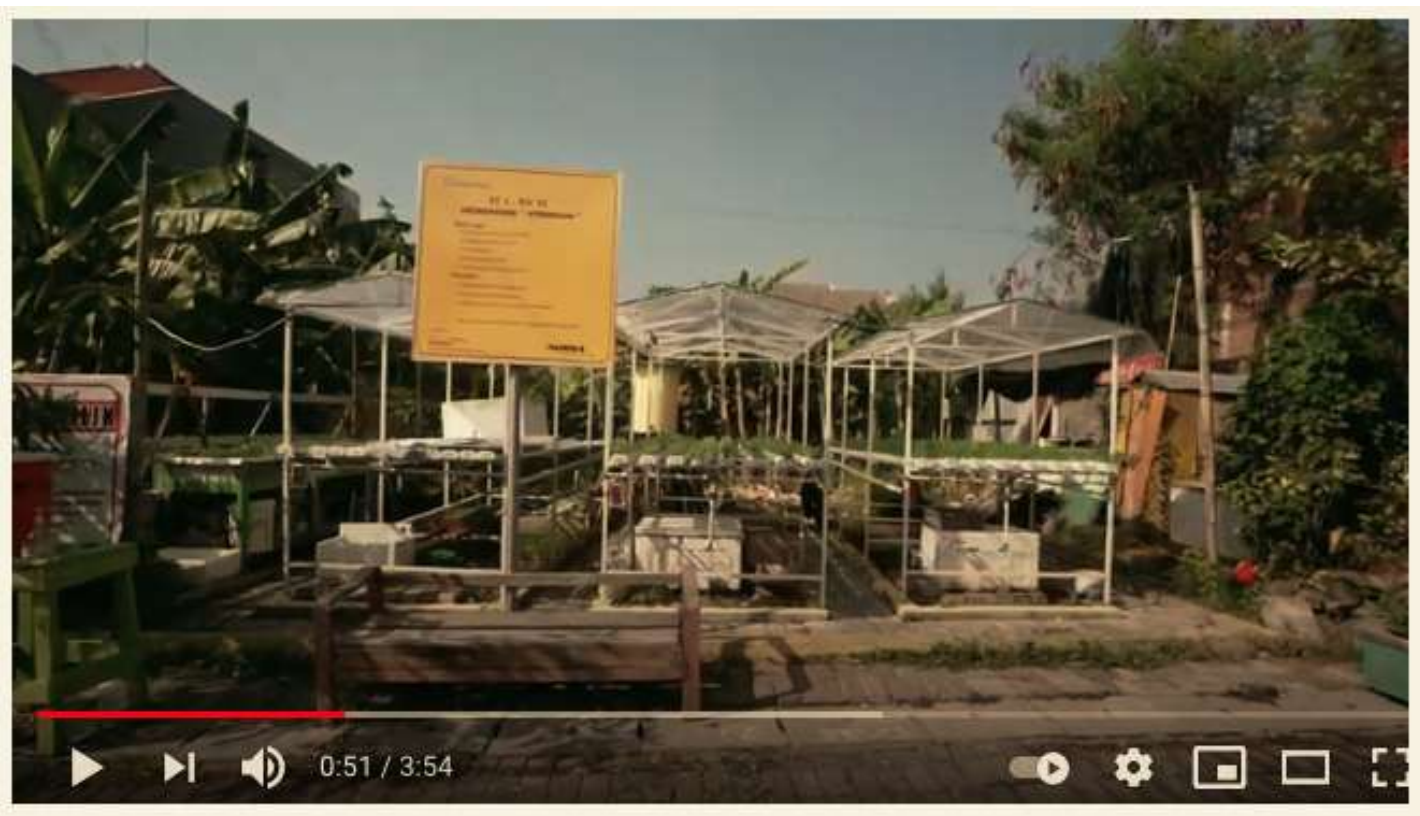

\section{KAMPUNG HIDROPONIK SURABAYA}

68 views $\cdot$ Jul 19,2020

$$
\text { I4 } 4 \text { II } 0 \Rightarrow \text { SHARE } \equiv+\text { SAVE } \ldots
$$

Gambar 6. Video Profil Kampung Hidroponik Surabaya

(sumber: https://www.youtube.com/watch?v=tTyCz1wSXTg, terakhir akses: 20

Februari 2021)

\section{Foto produk Tanaman Hidroponik untuk e-Commerce}

Kegitatan berikutnya adalah peningkatan penjualan melalui market place eCommerce. Kegiatan ini harus didukung dengan foto produk yang bagus dan menggambarkan produk unggulan dari Kampung Hidropononik ini secara mendetil sehingga dapat meningkatkan penjualan nantinya. Melalui foto produk yang dihasilkan ini akan dimasukan ke E-Commerce seperti Tokopedia, Bukalapak, dan Shopee.

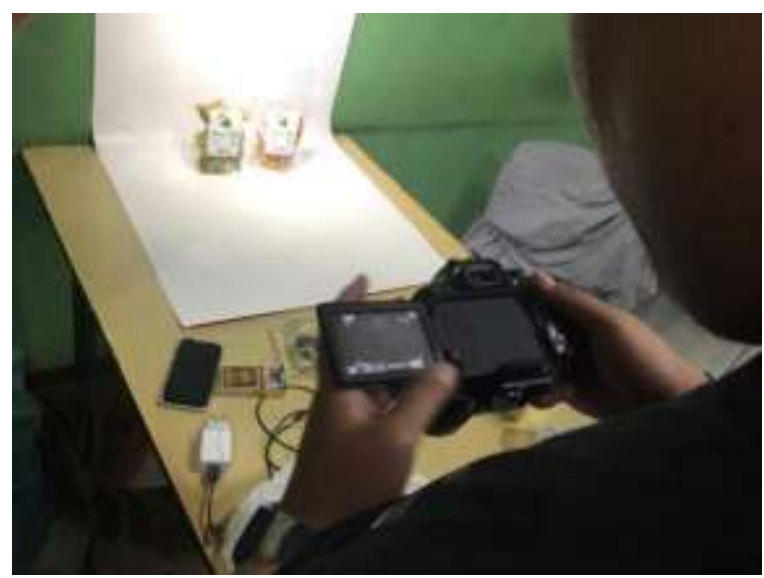

Gambar 6. Proses foto produk untuk keperluan eCommerce 


\section{Sosial Media Kampung Hidroponik Surabaya}

Pengelolan konten sosial media sebelumnya sudah dibuat dengan username @kampunghidroponiksurabaya, disini pengembangan digital branding yang dilakukan adalah memperbaiki postingan dengan desain-desain yang eye-catchy agar impresi pengguna Instagram tertarik untuk menekan tombol mengikuti. Lalu, untuk Facebook Fanpage akan kami perbarui juga dengan postingan-postingan yang mengedukasi.

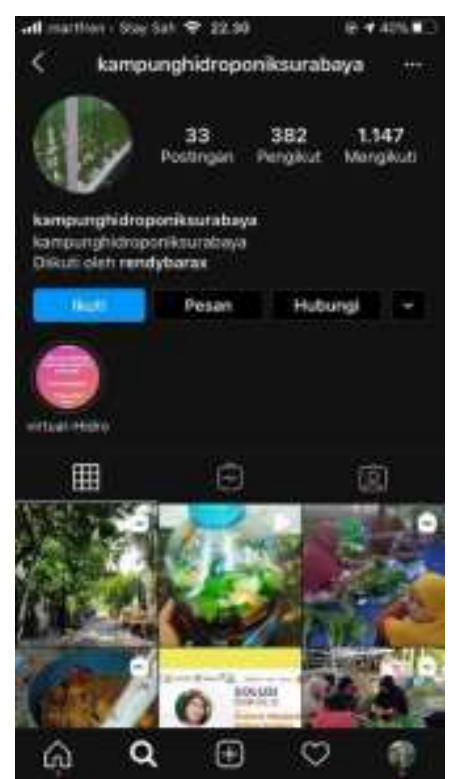

Gambar 7. Media Sosial Instagram Kampung Hidroponik Surabaya

\section{Pembuatan E-Commerce seperti Bukalapak, Tokopedia dan Shopee}

Pembuatan E-Commerce pun sudah dilaksanakan, yaitu Shopee, Tokopedia dan Bukalapak dengan nama Kampung Hidroponik Surabaya. Disini adalah wadah untuk masyarakat Kampung Hidroponik Medokan Ayu berjualan melalui online. Dari pelaksaanaan foto produk pada kegiatan ke 5, dimasukan disini sebagai konten pelengkap foto dari produk yang ditawarkan pada eCommerce.

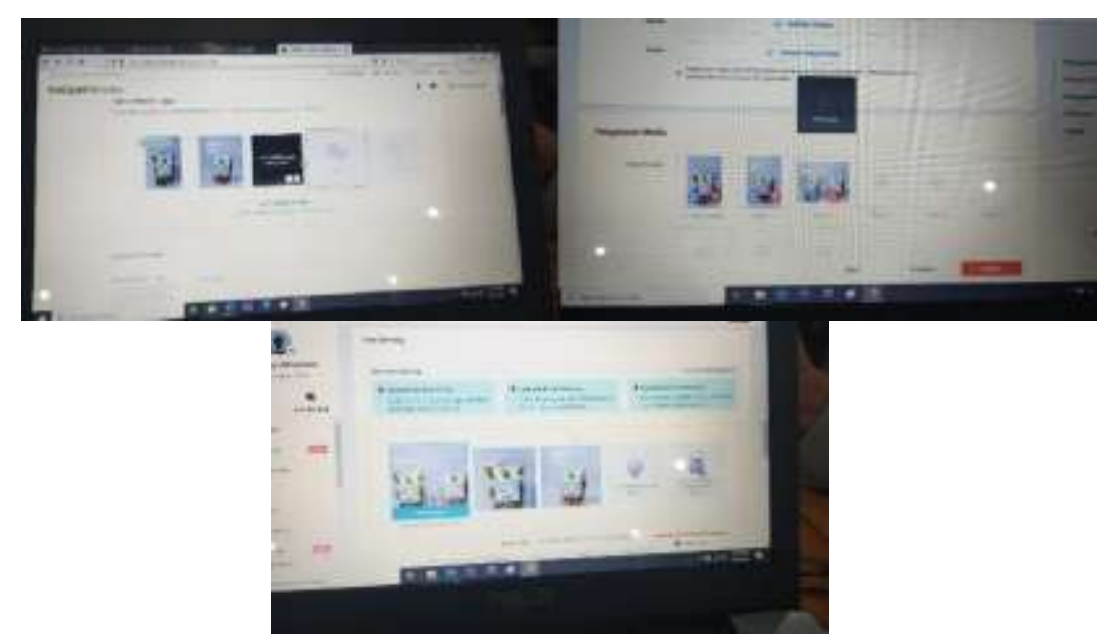

Gambar 8. Pembuatan E-Commerce seperti Bukalapak, Tokopedia, dan Shopee. 


\section{Sosialiasi tentang platform digital}

Kegiatan berikutnya adalah penjelasan tentang media komunikasi digital sebagai medium digital branding Kampung Hidroponik Medokan Ayu Surabaya. Sosialiasi ini dilakukan untuk memberikan pengetahuan seputar platform digital pada masyarakat RW 12 Medokan Ayu, dikarena adanya pandemi Covid-19 ini maka sosialisasi ini dilakukan secara daring melalui diskusi grup chat dan media sosial. Selanjutnya pemberian arahan dan sosialisasi platform digital ini dilakukan oleh koordinator kampung hidroponik, yaitu Ibu Reni. Ini bertujuan sebagai tindak lanjut pengembangan branding di platform digital secara berkesinambungan.

\section{Tutorial pembuatan Tanaman Hidroponik}

Pembuatan tutorial ini nantinya bertujuan untuk memberi edukasi pada penonton di sosial media Instagram untuk mengerti cara pembuatan tanaman hidroponik sendiri dirumahnya. Konsep yang diberikan dalam video tersebut, merupakan wawancara pada narasumber yaitu koordinator Kampung Hidroponik, Reni, lalu ditunjukan shoot bagaimana pembuatannya secara mandiri dirumah.

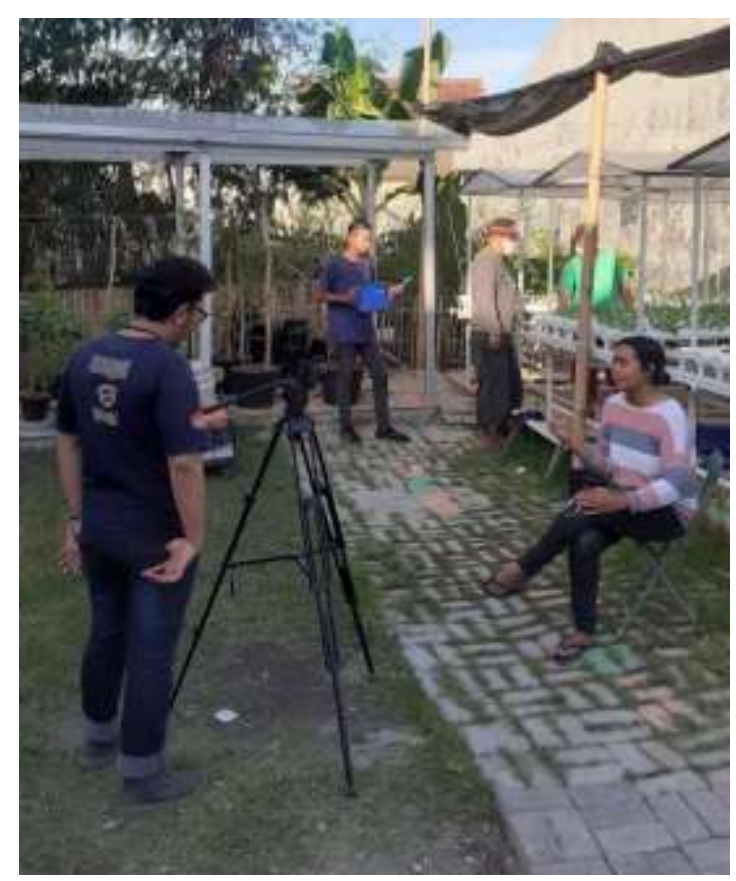

Gambar 9 Pelaksanaan take video Tutorial bersama ibu Reni selaku Koordinator Kampung Hidroponik 


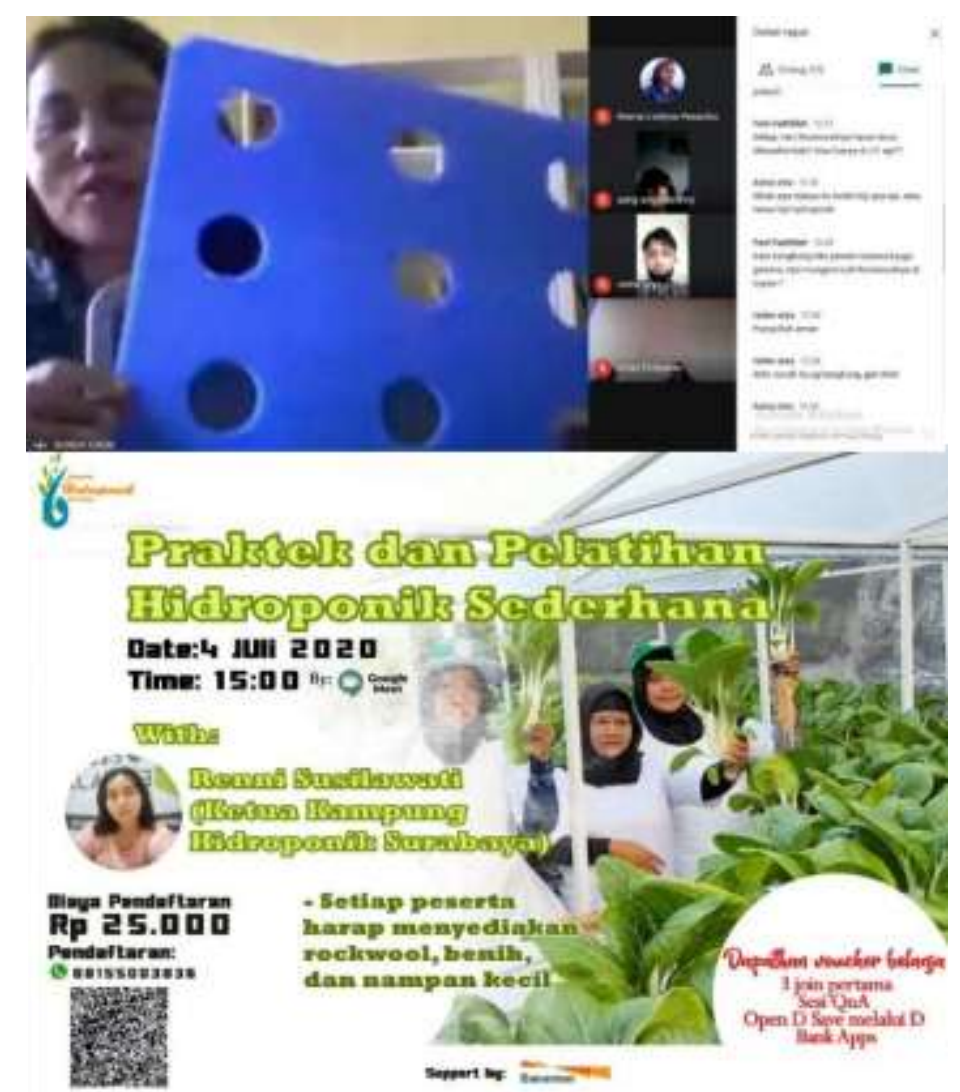

Gambar 10 Praktek dan pelatihan Hidroponik menggunakan medium digital

\section{Pembuatan banner untuk pengenalan Kampung Hidroponik Surabaya}

Pembuatan banner ini berfungsi sebagai pengenalan kebun-kebun tanaman hidroponik di Kampung Hidroponik Medokan Ayu. 4 (empat) kebun dengan nama MU, Guyub Rukun, Hybrid04, dan Hijau Kampungku. Selain itu, program kegiatan ini juga membuat banner untuk gazebo kampung hidroponik sebagai titik kumpul warga RT 4. Ucapan selamat datang juga kami buatkan sebagai penanda bahwa pengunjung sedang memasuki kawasan Kampung Hidroponik Medokan Ayu Surabaya.

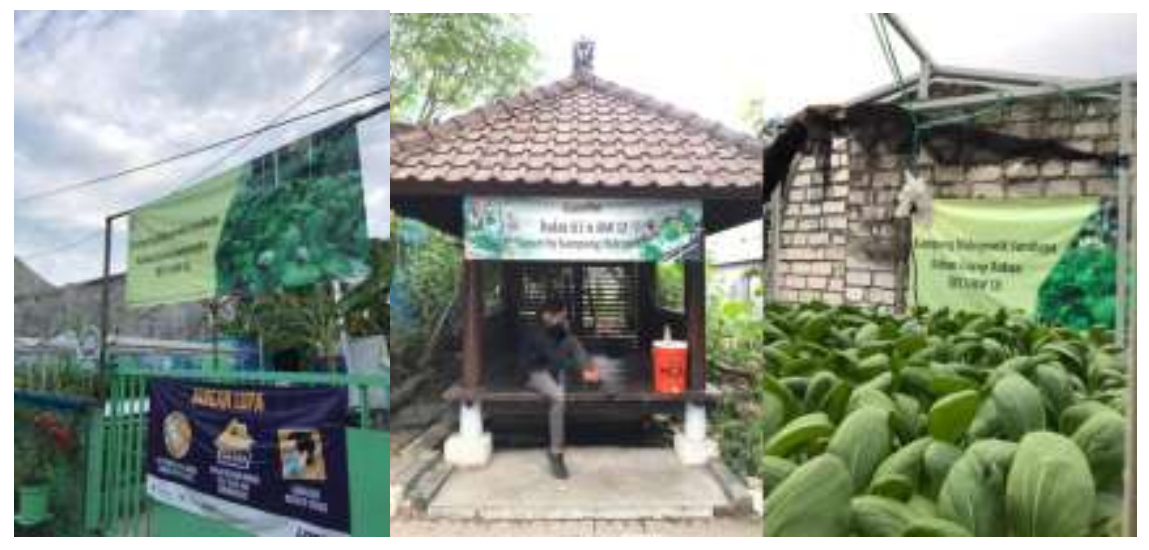

Gambar 11. Banner-banner sebagai penanda dan branding 


\section{PENUTUP}

Dari 9 program kerja yang sudah terlaksana, terdapat 2 (dua) program yang tidak dapat terlaksana dengan optimal, yaitu pembuatan kemasan dan sosialisasi media digital untuk masyarakat kampung Hidroponik Medokan Ayu. Ini dikarenakan pada waktu pelaksanaan yaitu bulan Mei-Juni terjadi pandemic Covid-19 kota Surabaya harus melakukan protokol kesehatan dengan menjaga jarak dan batasan kegiatan yang mengumpulkan massa, maka kegiatan sosialisasi dan pendampingan penggunaan media digital sebagai media digital branding belum terlaksana dengan optimal. Tetapi hal itu tidak menjadi kendala, akhirnya pelaksanaannya dilakukan secara daring (dalam jaringan) melalui medium Google Meet dan video tutorial. Sedangkan untuk pembuatan kemasan dari bahan kertas dengan food grade, masih dalam tahap konsep desain. Kedepan akan konsep ini dapat dilaksanakan dengan proses pembuatan kemasan yang lebih baik dan ramah lingkungan.

7 (tujuh) program dapat terlaksana secara optimal ini menunjukkan terwujudnya tujuan program pengabdian masyarakat ini dengan baik. Untuk pengembangan lebih lanjut sendiri nantinya akan diteruskan oleh warga Medokan Ayu Surabaya RW 12, khususnya pada anak-anak di usia muda. Saran yang dapat diberikan ke depan yaitu pada ketua RW 12 untuk melibatkan lebih aktif pada karang taruna untuk sosial media. Peran anak muda yang literasi digitalnya jauh lebih baik daripada orangtua dapat meningkatkan digital branding dari Kampung Hidroponik Medokan Ayu ini. Dengan meningkatnya digital branding maka dapat membantu penjualan dari produk unggulannya, ini akan meningkatkan ekonomi masyarakat dari Kampung Medokan Ayu.

\section{DAFTAR PUSTAKA}

Castells, M. (2011). The rise of the network society: The information age: Economy, society, and culture (Vol. 1). John Wiley \& Sons.

Cocoran, I. (2010). The art of digital branding. Simon and Schuster.

Djauhari, M., \& Afniar, A. (2018). Medium Komunikasi Pariwisata Melalui Film Animasi. Jurnal Spektrum Komunikasi, 6(2), 59-66.

Edelman, D. C. (2010). Branding in the digital age. Harvard Business Review, $88(12), 62-69$.

Kristiyono, J. (2017). BUDAYA INTERNET: PERKEMBANGAN TEKNOLOGI INFORMASI DAN KOMUNIKASI DALAM MENDUKUNG PENGGUNAAN MEDIA DI MASYARAKAT. Scriptura. https://doi.org/10.9744/scriptura.5.1.23-30

Kristiyono, J., \& Jayanti, O. R. (2017). Fake News (Hoax) and Paranoid Frame of Min of Social Media User. In 3rd International Conference on Transformation in Communications 2017 (IcoTiC 2017). Atlantis Press.

Murphy, J. M. (1992). What is branding? In Branding: A key marketing tool (pp. 112). Springer.

Rosliani, R., \& Sumarni, N. (2005). Budidaya tanaman sayuran dengan sistem hidroponik. Balai Penelitian Tanaman Sayuran. 
Jokhanan, dkk: Pengembangan Digital Branding Kampung Hidropononik Medokan Ayu Surabaya

Rowles, D. (2014). Digital branding: a complete step-by-step guide to strategy, tactics and measurement. Kogan Page Publishers.

Susilo, A. (2020). Aktivitas Cyber Public Relations Pada Agen Perjalanan Online Dalam Meningkatkan Brand Awareness. Jurnal Spektrum Komunikasi, 8(1), 22-29. 